\title{
COMMUNITY-ACQUIRED PNEUMONIA IN HIV-INFECTED PATIENTS
}

\author{
Omsk State Medical University, Omsk
}

\section{L.V. Puzyreva, M.A. Paneva}

\begin{abstract}
Community-acquired pneumonia is one of the causes of respiratory diseases in HIV-infected patients, especially in injecting drug users. To assess the studies of clinical implications of community-acquired pneumonia in patients being the injecting drug users, 69 cases of diseases were analysed in retrospect. Reliable differences in complaints of patients, general blood analysis and X-ray changes in pulmonary tissue in patients being injecting drug users were revealed.
\end{abstract}

Key words: community-acquired pneumonia, HIV infection, injecting drug users.

Respiratory diseases are one of the main causes of morbidity and mortality worldwide, with pneumonia taking the lead. The problem of pneumonia has always been of great scientific and practical interest. Recently, it has attracted even greater attention due to the spread of ARVI, influenza, and acquired immunodeficiency disorders contributing to the increase in the proportion of pneumonia in the population total morbidity [1].

Bacterial pneumonia is the main cause of morbidity and mortality among HIV-infected people, and its probability is 25 times higher than among the general population [2, 3, 4, 5]. In Europe, the development of recurrent bacterial pneumonia increased threefold (from 1.5\% to $4.6 \%$ ) after the beginning of ART in AIDS patients [6].

It is known that community-acquired bacterial pneumonia pathogenesis is closely associated with the use of injecting drugs, which is one of the main explanations for the changes in pulmonary tissue. In this group of patients, changes on the valves of the heart are often found; in the anamnesis, data on the past angiogenic sepsis are not rare. A frequent causative agent of pneumonia is Staphylococcus aureus, Haemophilus influenzae, and other microorganisms. The mortality rate from pneumonia in patients being the injecting drug users (IDUs) is $33.7 \%$, while the average in Russia among young patients is $1-3 \%[7,8]$.

The research objective is to compare clinical implications of community-acquired pneumonia in patients being the injecting drug users.

\section{Materials and methods}

69 cases of community-acquired pneumonia in HIV-infected patients treated in the in-patient hospitals of Omsk were analyzed retrospectively.

The patients were compared in two groups depending on the presence of signs of bacteriological endocarditis and angiogenic sepsis - it was the main group $(n=16)$. The experimental group $(n=53)$ consisted of patients with no signs of bacteriological endocarditis.

The work performed did not infringe on rights, did not endanger patients. The obtained data are processed using Statistica 6 software. Due to the presence of a distribution other than normal, methods of descriptive statistics with the calculation of non-parametric Pearson's $\chi^{2}$ test and Mann-Whitney U-test were applied. The data of the Me median were used. The results were considered significant at $\mathrm{p}<0.05$.

In both study groups, patients were comparable by sex, age, social status ( $\mathrm{p}>0.05)$.

\section{Results and discussion}

Most often the patients of the main study group entered the in-patient hospital through EFR - 87.5\% $(p=0.044$ ) against $60.4 \%$ in the experimental group.

At the time of admission, patients in both groups complained of weakness, ailment, decreased appetite, febrile temperature, cough, mostly wet, and dyspnea on exertion. However, patients in the main group often complained of muscle ache, joint ache $(37.5 \% ; \mathrm{p}<0.001)$, lack of appetite $(25.0 \%$; $\mathrm{p}<0.001)$, discomfort and chest pain, mostly on the left (25.0\%; $p=0.009)$, edema of legs $(31.3 \%$; $p=0.06)$, and diarrhea $(37.5 \%$; $\mathrm{p}<0.001)$ (Table 1$)$, which is often recorded in IDUs in the development of the clinic of septic inflammation [9].

In the analysis of the clinical stages of HIV infection at the time of admission to the in-patient hospital, the prevalence of patients from the main group in the stages of acute HIV infection with secondary diseases (2B) and subclinical stage 3 amounted to $75.0 \%$, and the number of patients in the control group in the stages of secondary diseases made $50.9 \%$ ( $p>0.05)$.

We calculated the experience of HIV infection from the moment of its registration to the day of treatment. In the main group and the experimental group, it amounted to 6 years in IU ( $U=414 ; p=0.88)$.

According to the results of immunological studies, in experimental groups, there are no statistically significant differences, except for the absolute number of CD4+ lymphocytes, the number of which is smaller in the experimental group (in $\mathrm{IU}, 288 \mathrm{cl} / \mu \mathrm{l}$, in the main group $-371 \mathrm{cl} / \mu \mathrm{l} ; \mathrm{U}=270.0$; $\mathrm{p}=0.02$ ), which corresponds to the clinical stages of HIV infection. 
Characteristics of complaints in patients of study groups, abs (\%)

\begin{tabular}{|l|c|c|c|}
\hline \multicolumn{1}{|c|}{ Sign } & The main group $(\mathrm{n}=16)$ & The control group $(\mathrm{n}=53)$ & $\chi^{2} / \mathrm{p}$ \\
\hline Weakness, ailment & $14(87.5)$ & $41(77.4)$ & $1.045 / 0.307$ \\
\hline Decreased appetite & $4(25.0)$ & $20(37.7)$ & $0.879 / 0.349$ \\
\hline lack of appetite & $4(25.0)$ & $0(0.0)$ & $14.06 / 0.001$ \\
\hline Muscle and joint ache & $6(37.5)$ & $0(0.0)$ & $21.768 / 0.001$ \\
\hline Cough & $16(100.0)$ & $45(84.9)$ & $2.732 / 0.099$ \\
\hline dry & $5(31.1)$ & $11(20.8)$ & $0.76 / 0.384$ \\
\hline wet & $11(68.8)$ & $34(64.2)$ & $0.115 / 0.735$ \\
\hline Dyspnea on exertion & $9(56.3)$ & $20(37.7)$ & $1.729 / 0.189$ \\
\hline at rest & $3(18.8)$ & $10(18.9)$ & $0.00 / 0.992$ \\
\hline Chest pain & $8(50.0)$ & $9(17.0)$ & $7.216 / 0.008$ \\
\hline on the left & $4(25.0)$ & $2(3.8)$ & $6.974 / 0.009$ \\
\hline on the right & $2(12.5)$ & $4(7.5)$ & $0.38 / 0.538$ \\
\hline with no clear localization & $2(12.5)$ & $3(5.7)$ & $0.855 / 0.356$ \\
\hline Headache & $1(6.3)$ & $4(7.5)$ & $0.031 / 0.861$ \\
\hline Vertigo & $1(6.3)$ & $8(15.1)$ & $0.848 / 0.358$ \\
\hline Nausea & $0(0.0)$ & $2(3.8)$ & $0.622 / 0.431$ \\
\hline Vomiting & $1(6.3)$ & $3(5.7)$ & $0.008 / 0.93$ \\
\hline Increased temperature & $15(93.8)$ & $48(90.6)$ & $0.157 / 0.693$ \\
\hline Edema of legs & $5(31.3)$ & $3(5.7)$ & $7.852 / 0.006$ \\
\hline Diarrhea & $6(37.5)$ & $0(0.0)$ & $21.76 / 0.001$ \\
\hline
\end{tabular}

More than $80.0 \%$ of HIV-infected patients did not take antiretroviral therapy when applying to a health facility because of complaints, which may have led to the development of secondary diseases $(\mathrm{p}>0.05)$.

At admission to the in-patient hospital, each second patient was more likely to have the moderate severity state, and almost every fourth patient was in critical condition in study groups ( $p>0.05$ ). The skin cover was pale in patients of the main group in $75.0 \%$, in the experimental group in $52.8 \%$ ( $>>0.05)$. In the case of respiratory auscultation, either rigid or rigid weakened breath in patients in study groups was listened. In rare cases, vesicular one was listened in the experimental group ( $p>0.05)$. In auscultation of mediastinal organs, clear rhythmic tones were listened in more than $70.0 \%$ of patients, and in case of palpation of abdominal organs, painlessness was diagnosed in more than $60.0 \%$ of patients in study groups. Half of the patients in each group showed an increase in the liver to $4 \mathrm{~cm}$ from the edge of the costal arch ( $p>0.05)$.

When admitted to the in-patient hospital, the body temperature in patients was $38.7^{\circ} \mathrm{C}$ in IU in both groups $(\mathrm{U}=404.0 ; \mathrm{p}=0.78)$. The frequency of respiratory movements at admission (IU 20 and 18 per minute; $U=405.0 ; p=0.78)$ and the pulse on the radial artery (IU 98 and 90; $\mathrm{U}=305.5 ; \mathrm{p}=0.09$ ) did not differ significantly.
In the general blood test, the value of hemoglobin in IU in the main group amounted to $100 \mathrm{~g} / \mathrm{l}$, in the experimental group $110 \mathrm{~g} / \mathrm{l}(\mathrm{U}=387.0 ; \mathrm{p}=0.598)$. The level of erythrocytes in the study groups was $2.6 \times 10^{12} / 1(\mathrm{U}=379.5 ; \mathrm{p}=0.521)$. Leukocytes in the main group were $9.5 \times 10^{9} / 1$, in the experimental group $6.4 \times 10^{9} / 1$ ( $\left.\mathrm{U}=284.0 ; \mathrm{p}=0.04\right)$. In both groups, erythrocyte sedimentation rate amounted to $42 \mathrm{~mm} / \mathrm{h}$ $(\mathrm{U}=391.5 ; \mathrm{p}=0.644)$.

In the leukogram and in the biochemical blood test, there are no significant differences in study groups ( $\mathrm{p}>0.05)$.

During the X-ray examination of chest organs, the following changes were revealed. The presence of infiltrative changes was revealed in all patients, both one- and bilateral $(p>0.05)$. It was found that the lesion of the middle right fraction was much more frequent in patients of the main group (43.8\%; $\mathrm{p}<0.01)$. Also, in IDUs with community-acquired pneumonia, destruction cavities in the pulmonary tissue were recorded in $56.3 \%$ of cases $(\mathrm{p}<0.01)$.

Both groups described the expansion of roots of lungs due to the increase in intrathoracic lymph nodes. One in four patients showed hydrothorax.

In the study of sputum for secondary microflora, Staphylococcus aureus was verified in IDUs with community-acquired pneumonia in $68.8 \%$ of cases $(\mathrm{p}<0.01)$ (Table 2). In the control group, Klebsiella pneumonia was revealed in sputum in $22.6 \%(\mathrm{p}<0.05)$. 
Data on the bacteriological study of sputum in patients of study groups, abs (\%)

\begin{tabular}{|l|c|c|c|}
\hline \multicolumn{1}{|c|}{ The causative agent } & The main group $(\mathrm{n}=16)$ & The control group $(\mathrm{n}=53)$ & $\chi^{2} / \mathrm{p}$ \\
\hline Staphylococcus aureus & $11(68.8)$ & $6(11.3)$ & $21.83 / 0.001$ \\
\hline $\begin{array}{l}\text { Pneumocystis jirovecii }+ \\
\text { Staphylococcus aureus }\end{array}$ & $1(6.25)$ & $1(1.9)$ & $0.831 / 0.362$ \\
\hline Escherichia coli. & $1(6.25)$ & $1(1.9)$ & $0.831 / 0.362$ \\
\hline Klebsiella pneumonia & $0(0.0)$ & $12(22.6)$ & $4.385 / 0.037$ \\
\hline $\begin{array}{l}\text { Klebsiella pneumonia }+ \\
\text { Staphylococcus aureus }\end{array}$ & $0(0.0)$ & $1(1.9)$ & $0.306 / 0.58$ \\
\hline Haemophilus influenzae & $0(0.0)$ & $5(9.4)$ & $1.627 / 0.203$ \\
\hline Pneumocystis jirovecii + undefined & $0(0.0)$ & $8(15.1)$ & $2.732 / 0.09$ \\
\hline Streptococcus viridans & $0(0.0)$ & $1(1.9)$ & $0.306 / 0.58$ \\
\hline Undefined & $3(18.8)$ & $18(34.0)$ & $1.343 / 0.247$ \\
\hline
\end{tabular}

Mainly, patients of both groups spent approximately the same number of bed-days in the in-patient hospital: 17 and 18 days $(\mathrm{U}=411.0 ; \mathrm{p}=0.85)$, and mortality was observed in $18.8 \%$ and $35.8 \%$ $\left(\chi^{2}=1.611 ; p=0.199\right)$ in the main group and control group respectively.

\section{Conclusion}

Thus, the study of patients being IDUs with community-acquired pneumonia revealed the following differences. Among the complaints, bone ache, muscle ache, lack of appetite, discomfort, chest pain, often on the left, edema of the legs, and diarrhea predominated. These patients admitted the in-patient hospital through EFR, which indicates the intensity of complaints and the severity of their condition. In the general blood test, leukocytosis and lymphopenia were observed, and destruction cavities, infiltrative changes in the middle right fraction were determined using X-ray. Staphylococcus aureus was verified in sputum in $68.8 \%$.

Therefore, when entering the in-patient hospital, it is necessary to determine the patient's predisposition to the injecting drug use, which will help in the choice of tactics of management and treatment of the patient.

Conflict of interest. The authors declare that there is no conflict of interest.

\section{References:}

1. Chuchalin A.G., Abrosimov V.N., Avdeev S.N. Pulmonology. National guide. Ed. A.G. Chuchalin. M., 2016: 800.

2. Gebo KA, Moore RD, Keruly JC, Chaisson RE. Risk factors for pneumococcal disease in human immunodeficiency virus-infected patients. $J$ Infect Dis. 1996; 173: 857-862.

3. Tumbarello M, Tacconelli E, de Gaetano Donati K, Ardito F, Pirronti T, Cauda R, et al. Bacterial pneumonia in HIV-infected patients: analysis of risk factors and prognostic indicators. J. Acquir Immune Defic Syndr Hum Retrovirol. 1998;18: 39-45.
4. Feikin DR, Feldman C, Schuchat A, Janoff EN. Global strategies to prevent bacterial pneumonia in adults with HIV disease. Lancet Infect Dis. 2004; 4: 445-455.

5. Zimina V.N., Astafyev A.V. Community-acquired pneumonia in adult HIV-infected patients: features of the course and treatment, prevention. Pulmonology. 2016; 4(26): 488-497.

6. Puro V, Serraino D, Piselli P, Boumis E, Petrosillo N, Angeletti C, et al. The epidemiology of AIDS associated recurrent bacterial pneumonia in Europe in the pre- and post-HAART periods [abstract 295]. In: Program and abstracts of 8th Conference on Retroviruses and Opportunistic Infection (Chicago). Alexandria, 2001: 131.

7. Ed. A.G. Chuchalin, A.I. Sinopalnikov. Clinical guidelines. Community-acquired pneumonia in adults. M., 2005: 200.

8. Androsova N.A., Bykonya I.N., Pudova A.N. et al. Clinicoradiological features of pneumonia in drug addicts. Journal of radiology and nuclear medicine. 2001; 2: 4-9.

9. Uteshev D.B., Karabinenko A.A., Filatova E.N., Storozhakov G.I. Infectious and septic complications in drug addicts. Lechaschii Vrach Journal. 2001; 1: 28-31.

\section{Contacts}

Corresponding author: Puzyreva Larisa Vladimirovna, Candidate of Medical Sciences, Head of the Department of Infectious Diseases, Omsk State Medical University, Omsk.

644099, Omsk, ul. Lenina, 12.

Tel.: (3812) 532666.

E-mail: puzirevalv@mail.ru

\section{Author information}

Paneva Marina Aleksandrovna, Candidate of Medical Sciences, Associate Professor of the Department of Hospital Therapy, Endocrinology, Omsk State Medical University, Omsk.

644099, Omsk, ul. Lenina, 12.

Tel.: (3812) 359362.

E-mail: rector@omsk-osma.ru 